\title{
Identifying priorities in methodological research using ICD-9-CM and ICD-I 0 administrative data: report from an international consortium
}

\author{
Carolyn De Coster*1,8, Hude Quan 1,2, Alan Finlayson³, Min Gao4, \\ Patricia Halfon ${ }^{5}$, Karin H Humphries ${ }^{6}$, Helen Johansen ${ }^{7}$, Lisa M Lix ${ }^{8}$, Jean- \\ Christophe Luthi ${ }^{5}$, Jin $\mathrm{Ma}^{9}$, Patrick S Romano ${ }^{10}$, Leslie Roos ${ }^{8}$, \\ Vijaya Sundararajan ${ }^{11}$, Jack V Tu ${ }^{12}$, Greg Webster ${ }^{13}$ and William A Ghali ${ }^{1,2,14}$
}

Address: ${ }^{1}$ Department of Community Health Sciences, University of Calgary, Calgary, Canada, ${ }^{2}$ Centre for Health and Policy Studies, University of Calgary, Calgary, Canada, ${ }^{3}$ Information Services, Healthcare Information Group, Edinburgh, UK, ${ }^{4}$ British Columbia Cardiac Registry, Vancouver, Canada, ${ }^{5}$ Institut Universitaire de Médecine Sociale et Préventive, University of Lausanne, Switzerland, ${ }^{6}$ Centre for Health Evaluation and Outcome Sciences, University of British Columbia, Vancouver, Canada, ${ }^{7} \mathrm{Health}$ Division, Statistics Canada, Ottawa, Canada, ${ }^{8} \mathrm{Manitoba}$ Centre for Health Policy, Department of Community Health Sciences, University of Manitoba, Winnipeg, Canada, ${ }^{9}$ Public Health College, Second Shanghai Medical University, Shanghai, China, ${ }^{10}$ University of California Davis School of Medicine, Davis, USA, ${ }^{11}$ Department of Human Services, Melbourne, Australia, ${ }^{12}$ Institute for Clinical Evaluative Sciences, Sunnybrook Health Sciences Centre, University of Toronto, Toronto, Canada,

${ }^{13}$ Canadian Institute for Health Information, Toronto, Canada and ${ }^{14}$ Department of Medicine, University of Calgary, Calgary, Canada

Email: Carolyn De Coster* - decoster@ucalgary.ca; Hude Quan - hquan@ucalgary.ca; Alan Finlayson - Alan.Finlayson@isd.csa.scot.nhs.uk; Min Gao - MGao@providencehealth.bc.ca; Patricia Halfon - Patricia.Halfon@chuv.ch;

Karin H Humphries - Khumphries@providencehealth.bc.ca; Helen Johansen - johahel@statcan.ca; Lisa M Lix - Lisa_Lix@cpe.umanitoba.ca; Jean-Christophe Luthi - Jean-Christophe.Luthi@chuv.ch; Jin Ma - majin@shsmu.edu.cn; Patrick S Romano - psromano@ucdavis.edu; Leslie Roos - Leslie_Roos@cpe.umanitoba.ca; Vijaya Sundararajan - Vijaya.Sundararajan@dhs.vic.gov.au; Jack VTu - tu@ices.on.ca;

Greg Webster - GWebster@cihi.ca; William A Ghali - wghali@ucalgary.ca

* Corresponding author

Published: I5 June 2006

BMC Health Services Research 2006, 6:77 doi:10.1186/1472-6963-6-77

This article is available from: http://www.biomedcentral.com/l472-6963/6/77

(C) 2006 De Coster et al; licensee BioMed Central Ltd.

This is an Open Access article distributed under the terms of the Creative Commons Attribution License (http://creativecommons.org/licenses/by/2.0), which permits unrestricted use, distribution, and reproduction in any medium, provided the original work is properly cited.

\begin{abstract}
Background: Health administrative data are frequently used for health services and population health research. Comparative research using these data has been facilitated by the use of a standard system for coding diagnoses, the International Classification of Diseases (ICD). Research using the data must deal with data quality and validity limitations which arise because the data are not created for research purposes. This paper presents a list of high-priority methodological areas for researchers using health administrative data.
\end{abstract}

Methods: A group of researchers and users of health administrative data from Canada, the United States, Switzerland, Australia, China and the United Kingdom came together in June 2005 in Banff, Canada to discuss and identify high-priority methodological research areas. The generation of ideas for research focussed not only on matters relating to the use of administrative data in health services and population health research, but also on the challenges created in transitioning from ICD-9 to ICD-I0. After the brain-storming session, voting took place to rank-order the suggested projects. Participants were asked to rate the importance of each project from I (low priority) to I0 (high priority). Average ranks were computed to prioritise the projects.

Results: Thirteen potential areas of research were identified, some of which represented preparatory work rather than research per se. The three most highly ranked priorities were the documentation of data fields in each country's hospital administrative data (average score 8.4), the translation of patient safety indicators from ICD-9 to ICD-I0 (average score 
8.0), and the development and validation of algorithms to verify the logic and internal consistency of coding in hospital abstract data (average score 7.0).

Conclusion: The group discussions resulted in a list of expert views on critical international priorities for future methodological research relating to health administrative data. The consortium's members welcome contacts from investigators involved in research using health administrative data, especially in cross-jurisdictional collaborative studies or in studies that illustrate the application of ICD-I0.

\section{Background}

Health administrative data are frequently used for health research in Canada and abroad. In the past two decades, such data have been widely employed by health services and population health researchers to study healthcare outcomes, effectiveness, appropriateness and utilization of healthcare services, and to investigate or monitor population health status and its determinants [1-11]. The varied and broad use of administrative data has been facilitated by important advantages of the data, including their accessibility, their wide geographic coverage and their relatively complete capture of contacts with the health system for a defined population $[12,13]$.

The use of health administrative data in health services research has been enabled by some key characteristics, notably the use of a standard system for coding diagnoses, the International Classification of Diseases (ICD). Established by the World Health Organization in 1893 to categorise causes of death, this system adopts a standardised format to code diagnoses, thereby enabling longitudinal and comparative studies [14]. The ninth revision, ICD-9, was expanded in 1977 to ICD-9-CM (Clinical Modification) to enable more precision in diagnostic codes, together with the addition of surgical intervention codes. In 1992, the $10^{\text {th }}$ Revision of ICD (ICD-10) was introduced. ICD-10 has been used by many countries throughout the world for coding cause of death and for hospital diagnoses since 1994 [15-17]. It has been used for mortality data since 2000 in Canada, and provinces have adopted ICD-10 for coding hospital diagnoses in a phased approach, beginning in 2001 .

One of the major advantages of ICD-10 is that it is far more detailed (there are a total of 12,420 codes in ICD-10 compared to 6,969 in ICD-9), permitting richer capture of clinical information. However, its implementation means that a number of established methodological tools applicable to ICD-9 or ICD-9-CM need to be redesigned for application in ICD-10. Another issue is that the structure of ICD-10 differs substantially from ICD-9. Furthermore, since each country licences the coding system individually from WHO and can create its own modifications, there may be more opportunity for discrepancies between countries. Finally, ICD-10 does not include procedure codes and so each country has developed its own coding system. The system used by Canada is the International Classification of Diseases, $10^{\text {th }}$ revision, Canadian version, Canadian Classification of Health Interventions (ICD-10-CA/CCI).

Clearly the implementation of ICD-10 offers many benefits while also raising significant challenges for the international health services and population health research communities. In addition, research using ICD administrative data must address other limitations, largely stemming from the fact that the data were created not for research but for other purposes. Data quality is a concern; errors in the data can stem from inaccurate or missing information in the patient record, from the failure to abstract relevant data, or from incorrect coding of the abstracted data. Another concern is that administrative data lack clinical details. Even when data quality is good, the diagnoses that are coded do not reflect the severity of disease, diagnostic findings are not coded, and clinical sequence is not available.

This paper describes the origins and first symposium of a new international group that has come together to discuss how to take advantage of these potential benefits, and to address the new and ongoing challenges associated with using administrative data in health services and population health research. International collaborative research on health services has many advantages. From the methodological perspective, such research allows investigators to develop analytic tools that are more robust and more generalisable. It also allows those tools to be adopted in a systematic and uniform manner across countries, thereby fostering international exchange of research data and findings. From the policy perspective, it helps us to understand the strengths and weaknesses of various healthcare systems, and identifies opportunities for improvement in those systems.

\section{The consortium}

The consortium came together through a fortuitous set of circumstances. Australian researcher Vijaya Sundararajan contacted Canadian researchers William Ghali and Hude Quan because they were all doing similar work. While on sabbatical, William Ghali met Swiss researchers with similar interests: Patricia Halfon, Jean-Christophe Luthi and Bernard Burnand. These links led to two initial collabora- 
tive projects: new ICD-10 coding algorithms for two widely-used comorbidity measures, the Charlson index and the Elixhauser comorbidity categories [18].

Meanwhile the Canadian Institutes of Health Research (CIHR) announced a funding opportunity for workshops. A successful proposal by Ghali and Quan to the Institute for Health Services and Policy Research permitted a seminar and workshop held June 17 and 18, 2005 in Calgary and Banff, Alberta. The objectives of the workshop were to:

1) solidify collaborative relationships through a face-toface meeting of researchers;

2) initiate dialogue around launching a set of collaborative research projects on methodological issues surrounding the use of administrative data; and

3) stage a symposium in parallel to the workshop meetings at which the invited researchers would present their work to interested attendees.

Additional invitees to the seminar and workshop included representatives from two stakeholder organizations (Canadian Institute for Health Information (CIHI), and Statistics Canada), five Canadian collaborators, and investigators from the United States, the United Kingdom, Australia, Switzerland and China. The list of invited participants was a convenience sample whose selection was based on two criteria: they were bona fide experts in this area and/or they were known to the organisers.

\section{Methods}

The Seminar was held on the morning of June 17 at the Faculty of Medicine, University of Calgary. Members of the international consortium gave 11 presentations to an audience of approximately 100 people, with participants from not only Calgary, but also Edmonton, Vancouver and Ontario. The workshop presentations included descriptions of administrative data systems in Switzerland, Scotland and China, and the use of administrative data to measure comorbidities, chronic disease prevalence, quality of care and waiting times.

The research planning workshop followed on Saturday, June 18 in Banff. The atmosphere was informal and collaborative. The morning sessions covered such topics as the validity of administrative data, analysis of administrative data by Statistics Canada, premature mortality in Scotland and Europe, and opportunities for using CIHI data for research. The group then engaged in a focussed discussion around ideas for future collaborative research projects necessary to advance this field. The emphasis in this research planning discussion was on high-priority methodological areas in need of research that the consortium could undertake collectively in future work. Some of the areas identified represent preparatory work rather than research per se.

\section{Results}

Thirteen potential areas of research were identified.

1. 'Meta-data' documentation of international administrative data: Every field in each country's hospital administrative data system would be defined and described. While not as exciting as more applied projects, a compilation of this nature would be necessary for international comparative studies, and would also serve to highlight identified problems or issues with the data from specific countries.

2. International cross-validation of new ICD-10 coding algorithms. ICD-10 versions of the Charlson and Elixhauser comorbidity indices have been developed, as mentioned previously. There has been some initial work comparing the results of the new Charlson coding algorithms across countries, but more work is necessary. ICD10 coding algorithms need to be developed in other areas, for example chronic diseases, along with additional international comparisons

3. Patient safety indicators (PSI) translation: PSIs have been developed using ICD9-CM coding, under the auspices of the U.S. Agency for Healthcare Research and Quality, but corresponding ICD-10 codes for these indicators have not yet been developed. The PSIs are designed to screen for potentially preventable adverse effects of hospitals care. By translating the PSIs into ICD-10 and then validating this translation using data that have been independently coded according to both ICD-9-CM and ICD-10, researchers will be able to compare inpatient safety across national boundaries.

4. Learning curves: This effort would focus on the timing of uptake of ICD-10, and whether data validity assessments indicate the presence of a learning curve for coding. Canada, with its phased implementation in multiple provinces over several years, would be an ideal setting for this type of work.

5. Training standards for health record coders: It was discovered at the workshop that hospital abstract coders receive very different training from country to country. This project would explore those issues further with formal documentation of training requirements and practice guidelines for health record coders in various countries.

6. Chart-Database comparison studies: This would involve medical record reviews to determine the validity of hospital abstract data compared with the patient record 
across multiple countries. These are very expensive studies, especially if international comparisons are involved, but they would help researchers to characterise the importance of reporting and coding bias in international studies using administrative healthcare data.

7. Internal consistency algorithms: Algorithms can be developed to verify the logic of codes. For example, diabetic retinopathy should not occur in a patient who has never had a diagnosis of diabetes; prostatectomies cannot occur in females. Some work of this type has already been done in Switzerland and California. Different algorithms could be tested, refined, validated and then made available to others.

8. "True" gold standard: The purpose of this research would be to verify whether the trusted gold standard in observational health research, the patient's medical record, is in fact valid when compared to a 'truer' gold standard of information collected prospectively from patients and providers during a medical encounter. This research would require real-time patient assessments by independent clinicians who would observe all of the patient's interactions with physicians, as well as all of the discussions among the physicians involved in establishing and treating the patient's diagnosis. Comparisons would then be made between the independent assessment, the patient record, a nurse reviewer, and administrative data.

9. Travelling coders for comparative recoding: This research would require travelling coders who would recode previously coded records across countries to assess uniformity. By using a single team of travelling coders, researchers could estimate the nature and magnitude of international differences in coding practices.

10. Interventional studies to enhance coding quality: This research might include, for example, randomised controlled trials or pre-post studies to determine the effectiveness of educational or system interventions aimed at improving coding quality.

11. Value of diagnosis type coding: Some countries (or individual states or provinces) include a diagnosis-type code indicating whether each diagnosis is a comorbidity or a complication. Research in this area would focus on demonstrating the value of diagnosis-type codes, their validity, and the economic and human resources impact of implementation.

12. International comparisons of predictive model performance, as measured by the $\mathrm{C}$ (concordance)-statistic: It was determined from the group's presentations that $\mathrm{C}$-statistic values differ across countries in comorbidity-based mortality predictions, but it is not understood why. The Cstatistic is a measure of the discriminative accuracy of a logistic regression model $[19,20]$. The difference in C-statistic values may depend on the number of diagnosis fields available in abstracts, as well as the underlying coding validity and the epidemiology of disease in the population. Research in this area would aim to uncover the factors that contribute to the observed differences in model performance.

13. International scan of privacy considerations across countries and implications regarding permissible linkage activities: Discussions at the workshop revealed that there are considerable differences between countries in permissible data linkage activities, which have a great impact on the types of health services research that is possible.

After the brain-storming session, voting took place to rank-order the suggested projects. Participants were asked to rate the importance of each project from 1 (low importance), to 10 (high importance). Average ranks were computed to prioritise the projects (Table 1). While all projects were considered to be of at least moderate importance, several priorities emerged, in particular, research into international meta-data documentation and translation of patient safety indicators.

\section{Discussion}

Objectives were achieved; the workshop was considered by all to be a big success and a memorable event. Valuable face-to-face contacts were made and the addition of outdoor activities on Sunday June 19 helped to solidify linkages between participants. The group discussions resulted in a list of expert views on critical international priorities for future methodological research relating to health administrative data. It must be acknowledged, however, that the list was limited by the experience and knowledge of the experts who attended the meeting and as such, it is certainly possible that the list omits key issues that others would consider to be important.

Since the symposium, work has continued. A paper is in preparation comparing three ICD-10 translations of the Charlson comorbidity index that were developed in Switzerland, Australia, and Canada. Within Canada, trends in the coding of Charlson comorbidities are being analyzed, assessing the impact and learning curve associated with the phased introduction of ICD-10. Preparatory dialogue is underway to plan the implementation of additional projects in the research areas outlined in the table.

\section{Knowledge exchange}

The consortium is committed to the dissemination and sharing of knowledge with the broader health services and population health research communities. The PowerPoint 
Table I: Ranking of research areas in order of importance for administrative data research

\begin{tabular}{|c|c|c|c|}
\hline Project & Mean score & Number of raters & Priority Rank \\
\hline Meta-Data documentation & 8.4 & 10 & I \\
\hline Patient safety indicators translation & 8.0 & 10 & 2 \\
\hline Internal consistency algorithms & 7.0 & 10 & 3 \\
\hline $\begin{array}{l}\text { Interventional studies to enhance } \\
\text { coding quality }\end{array}$ & 6.9 & 10 & 4 \\
\hline "True" gold standard & 6.8 & 10 & 5 \\
\hline $\begin{array}{l}\text { Travelling coders for comparative } \\
\text { recoding }\end{array}$ & 6.8 & 9 & 5 \\
\hline $\begin{array}{l}\text { Training standards for health } \\
\text { records coders }\end{array}$ & 6.4 & 10 & 7 \\
\hline $\begin{array}{l}\text { International comparisons of } \\
\text { predictive model performance (C- } \\
\text { statistic) }\end{array}$ & 6.2 & 10 & 8 \\
\hline Value of diagnosis-type coding & 6.0 & 9 & 9 \\
\hline $\begin{array}{l}\text { Chart-Database comparison } \\
\text { studies }\end{array}$ & 5.9 & 10 & 10 \\
\hline $\begin{array}{l}\text { International cross-validation of } \\
\text { ICD-10 coding algorithms }\end{array}$ & 5.8 & 10 & 11 \\
\hline $\begin{array}{l}\text { International scan of privacy } \\
\text { considerations }\end{array}$ & 5.6 & 10 & 12 \\
\hline Learning curve in ICD-10 uptake & 5.0 & 10 & 13 \\
\hline
\end{tabular}

presentations from the seminar are available on the website of the Centre for Health and Policy Studies, University of Calgary [21]. Useful websites which describe methodological tools, key concepts and operational definitions emanating in part from the work of consortium members include the Manitoba Centre for Health Policy's concept index [22], the Centre for Health and Policy Studies [21], the Institut Universitaire de Médecine Sociale et Préventive [23], AHRQ's quality indicators [24], and the Canadian Institute for Health Information [25].

The consortium's members welcome contacts from investigators involved in research using health administrative data, especially in cross-jurisdictional collaborative studies and/or in studies that illustrate the application of ICD10. All attendees indicated commitment to carry forward the enthusiasm evident at this inaugural workshop, and hoped to hold future consortium meetings to advance the exciting and important work of this international group.

\section{Competing interests}

The author(s) declare that they have no competing interests.

\section{Authors' contributions}

HQ and WAG obtained the funding for the workshop, organised and facilitated it, and assisted in drafting the manuscript; CD drafted the manuscript; all participants were actively engaged in the workshop, contributed to the discussions and ratings about priority areas for future collaborative research, and participated in revising the paper and reviewing the final version for submission.

\section{Acknowledgements}

We thank Fatima Chatur who provided administrative and organizational support for the seminar and workshop. We also thank the Institute of Health Services and Policy Research, Canadian Institutes of Health Research, for funding the seminar and workshop.

\section{References}

I. Wennberg J, Gittelsohn A: Small Area Variations in Health Care Delivery. Science 1973, I82: I 102-II08.

2. Magid DJ, Calonge BN, Rumsfeld JS, Canto JG, Frederick PD, Every NR, Barron HV, National Registry of Myocardial Infarction: Relation between hospital primary angioplasty volume and mortality for patients with acute MI treated with primary angioplasty vs. thrombolytic therapy. JAMA 2000, 284:3|3|-3|38.

3. Schrag D, Cramer LD, Bach PB, Cohen AM, Warren JL, Begg CB Influence of hospital procedure volume on outcomes following surgery for colon cancer. JAMA 2000, 284:3028-3035.

4. Rosenthal GE, Harper DL, Quinn LM, Cooper GS: Severityadjusted mortality and length of stay in teaching and nonteaching hospitals. Results of a regional study. JAMA I997, 278:485-490.

5. Asch SM, Sloss EM, Hogan C, Brook RH, Kravitz RL: Measuring underuse of necessary care among elderly Medicare beneficiaries using inpatient and outpatient claims. JAMA 2000, 284:2325-2333.

6. May DS, Kelly J], Mendlein JM, Garbe PL: Surveillance of major causes of hospitalization among the elderly, 1988. Morbidity \& Mortality Weekly Report I99I, 40:7-2 I. CDC Surveillance Summaries

7. Roos LL, Roos NP, Cageorge SM, Nicol JP: How good are the data? Reliability of one health care data bank. Med Care 1982, 20:266-276.

8. Virnig $B A, M c B e a n ~ M$ : Administrative data for public health surveillance and planning. Annu Rev Public Health 200I, 22:2 I3-230.

9. Goff DC Jr, Pandey DK, Chan FA, Ortiz C, Nichaman MZ: Congestive heart failure in the United States: is there more than meets the I(CD code)? The Corpus Christi Heart Project. Arch Intern Med 2000, I 60: 197-202.

10. Bernstein CN, Blanchard JF, Rawsthorne P, Wajda A: Epidemiology of Crohn's disease and ulcerative colitis in a central Canadian province: a population-based study. Am J Epidemiol 1999, 149:916-924. 
II. Hamilton WT, Round AP, Sharp D, Peters TJ: The quality of record keeping in primary care: a comparison of computerised, paper and hybrid systems. BrJ Gen Pract 2003, 53:929-933.

12. Mitchell JB, Bubolz T, Paul JE, Pashos CL, Escarce J], Muhlbaier LH, Wiesman JM, Young WW, Epstein RS, Javitt JC: Using Medicare claims for outcomes research. Med Care 1994, 32:|S38-JS5 I.

13. Deyo RA, Taylor VM, Diehr P, Conrad D, Cherkin DC, Ciol M, Kreuter $\mathrm{W}$ : Analysis of automated administrative and survey databases to study patterns and outcomes of care. Spine 1994, 19:2083S-209/S.

14. Joffres MR, Ghadirian P, Fodor JG, Petrasovits A, Chockalingam A, Hamet $P$ : Awareness, treatment and control of hypertension in Canada. Am J Hypertens 1997, 10:1097-I I02.

15. De Lusignan S, Minmagh C, Kennedy J, Zeimet M, Bommezijn H, Bryant J: A survey to identify the clinical coding and classification systems currently in use across Europe. Medinfo 200I, 10:86-89.

16. Brouch K: Where in the world is ICD-I0? J AHIMA 2000, 71:52-57.

17. Hux JE, Ivis F, Flintoft V, Bica A: Diabetes in Ontario: determination of prevalence and incidence using a validated administrative data algorithm. Diabetes Care 2002, 25:5।2-516.

18. Quan H, Sundararajan V, Halfon P. Fong A, Burnand B, Luthi IC, Saunders LD, Beck CA, Feasby TE, Ghali WA: Coding algorithms for defining comorbidities in ICD-9-CM and ICD-10 administrative data. Med Care 2005, 43: I I30-II39.

19. Ghali WA, Quan H, Brant R, van Melle G, Norris CM, Faris P, Knudtson ML, for the APPROACH Investigators: A comparison of two methods for calculating adjusted survival curves from proportional hazards models. JAMA 200I, 286: I 494-I497.

20. Sundararajan V, Henderson T, Perry C, Muggivan A, Quan H, Ghali W: New ICD-I 0 version of the Charlson comorbidity index predicts in hospital mortality. J Clin Epidemiol 2004, 57:1288-1294

21. Centre for Health and Policy Studies, University of Calgary [http://www.chaps.ucalgary.ca/hquan.htm]

22. Manitoba Centre for Health Policy, University of Manitoba [http://umanitoba.ca/centres/mchp/concept]

23. Institut Universitaire de Médecine Sociale et Préventive [http://iumsp.ch]

24. Agency for Healthcare Research and Quality [http://qualityin dicators.ahrq.gov]

25. Canadian Institute for Health Information [http://cihi.ca]

\section{Pre-publication history}

The pre-publication history for this paper can be accessed here:

http://www.biomedcentral.com/1472-6963/6/77/prepub

Publish with Bio Med Central and every scientist can read your work free of charge

"BioMed Central will be the most significant development for disseminating the results of biomedical research in our lifetime. "

Sir Paul Nurse, Cancer Research UK

Your research papers will be:

- available free of charge to the entire biomedical community

- peer reviewed and published immediately upon acceptance

- cited in PubMed and archived on PubMed Central

- yours - you keep the copyright
BioMedcentral 